\title{
Chronotherapeutic effect of orexin antagonists on glucose metabolism in diabetic mice
}

\author{
Kanta Kon 1,*, Hiroshi Tsuneki ${ }^{1, *}$, Hisakatsu Ito², Yoshinori Takemura², Kiyofumi Sato', Mitsuaki Yamazaki ${ }^{2}$, \\ Yoko Ishii ${ }^{3}$, Masakiyo Sasahara3 ${ }^{3}$ Assaf Rudich4, Takahiro Maeda1, Tsutomu Wada1 and Toshiyasu Sasaoka1 \\ 'Department of Clinical Pharmacology, University of Toyama, Sugitani, Toyama, Japan \\ 2Department of Anesthesiology, University of Toyama, Sugitani, Toyama, Japan \\ 3Department of Pathology, University of Toyama, Sugitani, Toyama, Japan \\ ${ }^{4}$ Department of Clinical Biochemistry and Pharmacology, Ben-Gurion University of the Negev, Beer-Sheva, Israel
}

Correspondence should be addressed to T Sasaoka or H Tsuneki: tsasaoka@pha.u-toyama.ac.jp or htsuneki@pha.u-toyama.ac.jp

*(K Kon and $\mathrm{H}$ Tsuneki contributed equally to this work)

\begin{abstract}
Disrupted sleep is associated with increased risk of type 2 diabetes. Central actions of orexin, mediated by orexin-1 and orexin-2 receptors, play a crucial role in the maintenance of wakefulness; accordingly, excessive activation of the orexin system causes insomnia. Resting-phase administration of dual orexin receptor antagonist (DORA) has been shown to improve sleep abnormalities and glucose intolerance in type 2 diabetic $d b / d b$ mice, although the mechanism remains unknown. In the present study, to investigate the presence of functional link between sleep and glucose metabolism, the influences of orexin antagonists with or without sleep-promoting effects were compared on glucose metabolism in diabetic mice. In $d b / d b$ mice, 2-SORA-MK1064 (an orexin-2 receptor antagonist) and DORA-12 (a DORA) acutely improved non-rapid eye movement sleep, whereas 1-SORA-1 (an orexin-1 receptor antagonist) had no effect. Chronic resting-phase administration of these drugs improved glucose intolerance, without affecting body weight, food intake, locomotor activity and energy expenditure calculated from $\mathrm{O}_{2}$ consumption and $\mathrm{CO}_{2}$ production. The expression levels of proinflammatory factors in the liver were reduced by 2-SORA-MK1064 and DORA-12, but not 1-SORA-1, whereas those in the white adipose tissue were reduced by 1-SORA-1 and DORA-12 more efficiently than 2-SORA-MK1064. When administered chronically at awake phase, these drugs caused no effect. In streptozotocin-induced type 1-like diabetic mice, neither abnormality in sleep-wake behavior nor improvement of glucose intolerance by these drugs were observed. These results suggest that both 1-SORA-type (sleep-independent) and 2-SORA-type (possibly sleep-dependent) mechanisms can provide chronotherapeutic effects against type 2 diabetes associated with sleep disturbances in $d b / d b$ mice.
\end{abstract}
Key Words
- orexin/hypocretin
- diabetes
- sleep disturbances
- chronic inflammation
- chronotherapy

\section{Introduction}

The prevalence of lifestyle-related disorders, including insomnia, obesity and type 2 diabetes is increasing worldwide, mainly due to dramatic changes in living environments in modern society. Evidence indicates that environmental and behavioral circadian misalignments in modern lifestyle, such as shift work and late eating, 
lead to dysregulation of glucose metabolism and increased risk of type 2 diabetes (Cedernaes et al. 2015, Qian et al. 2016). Intriguingly, one night of partial sleep deprivation is enough to cause insulin resistance in healthy humans (Donga et al. 2010). Unbalanced regulations of the hormonal and autonomic nervous systems contribute to the disrupted sleep-induced impairment of glucose metabolism (Knutson \& Van Cauter 2008, Qian et al. 2016). Several studies have demonstrated that behavioral interventions for optimizing sleep duration improve glucose metabolism; however, it remains uncertain whether drug treatment of insomnia could improve glucose metabolism in diabetic patients (Reutrakul \& Van Cauter 2018).

Orexin receptors have emerged as a novel class of therapeutic target against insomnia since the role of hypothalamic orexin system in the promotion of wakefulness and motivated behavior was uncovered (Mahler et al. 2014, Tsuneki et al. 2018). Central levels of orexin increase daily at awake phase and activate two types of orexin receptors, orexin-1 and -2 receptors. Orexin- 2 receptors play a major role in the stabilization of wakefulness by regulating transition between non-rapid eye movement (NREM) sleep and wakefulness state. Rapid eye movement (REM) sleep is negatively controlled by both orexin-1 and -2 receptors (Tsuneki et al. 2018). Accordingly, DORAs promote both NREM and REM sleep, and selective orexin-2 receptor antagonists (2-SORAs) efficiently promote NREM sleep in rodents as well as humans (Mieda 2017). Selective orexin-1 receptor antagonists (1-SORAs) alone often have no effect on the baseline sleep-wake state, although 1-SORAs can enhance the sleep-promoting effects of 2-SORAs (Morairty et al. 2012, Mieda 2017). Based on these profiles, the effects of many DORAs and 2-SORAs have been intensively studied to develop a new therapeutic drug against insomnia (Andrews et al. 2016). 1-SORAs prevent hedonic motivation; therefore, they are considered useful in preventing drug addiction and addiction-like eating (Tsuneki et al. 2018).

We have previously investigated the effect of suvorexant, a DORA used in the therapy for insomnia, in type 2 diabetic $d b / d b$ mice (Tsuneki et al. 2016a). The sleep-wake architecture was impaired in $d b / d b$ mice. Resting-phase administration of suvorexant improved both sleep abnormalities and glucose intolerance (Tsuneki et al. 2016a). A recent clinical study also demonstrated that suvorexant improved glycemic control in type 2 diabetic patients with insomnia (Toi et al. 2019). Restingphase administration of SB-334867, a 1-SORA, has been reported to exert anti-obesity effect, thereby increasing insulin sensitivity in obese $o b / o b$ mice (Haynes et al. 2002). The effects of 2-SORAs on glucose metabolism have not been tested. Therefore, it remains unclear whether DORAs improve glucose metabolism by either or both of 1-SORA-type (i.e., sleep-independent) and 2-SORA-type (i.e., possibly sleep-dependent) mechanism. We hypothesized that if a sleep-dependent mechanism exists and 2-SORA can promote it, DORA would provide the synergistic benefits of both 1-SORA and 2-SORA on glucose metabolism. Thus, analysis of the pharmacological profiles of 1-SORAs, 2-SORAs and DORAs may clarify the relationship between the regulations of sleep and glucose metabolism.

In the present study, we therefore compared the effects of 1-SORA-1 (a 1-SORA; Stump et al. 2016), MK1064 (a 2-SORA, indicated as 2-SORA-MK1064 below; Gotter et al. 2016) and DORA-12 (a DORA classified as a structural analog of suvorexant; Cox et al. 2010, Gotter et al. 2012) on sleep-wake behavior and glucose metabolism in type 2 diabetic $d b / d b$ mice. We also investigated the sleepwake pattern and the mode of actions of these drugs in streptozotocin (STZ)-induced type 1-like diabetic mice, since both remain unknown. The present study may provide evidence that pharmacological interventions for optimizing sleep quality and/or quantity are valuable for improving glucose metabolism under the diabetic conditions.

\section{Materials and methods}

\section{Materials}

(S)-(4,4-difluoro-3-(quinolin-2-yloxy)piperidin-1-yl) (1H-imidazo[4,5-c]pyridin-4-yl) methanone (1-SORA-1), MK-1064 (2-SORA-MK1064), DORA-12 and (R)-3-(4-(5chlorobenzo[d]oxazol-2-yl)-7-methyl-1,4-diazepane1-carbonyl)-4-(2H-1,2,3-triazol-2-yl)benzamide (DORA-P) were provided by Merck \& Co.. Diazepam, a benzodiazepine class of $\gamma$-aminobutyric acid (GABA)-A receptor modulator, was purchased from Wako Pure Chemical. These drugs were suspended in $0.5 \%$ methyl cellulose 400 (Wako) just before the oral administration. Insulin (Humulin-R) was from Eli Lilly. 1-SORA-1 is $>400-$ fold selective for orexin-1 over -2 receptor (Stump et al. 2016), whereas 2-SORA-MK1064 is >1100-fold selective for orexin-2 over -1 receptor (Gotter et al. 2016). DORA-12 exhibits similar affinity for both receptor subtypes ( $<10$-fold higher affinity to orexin- 2 over -1 receptor) (Gotter et al. 2012). DORA-P is a blood-brain barrier 
(BBB)-impermeable compound with a high basolateralapical vs apical-basolateral (BA/AB) ratio (e.g., $\mathrm{BA} / \mathrm{AB}$ of 22.6 in rats), and did not affect sleep-wake pattern at least at a low dose $(30 \mathrm{mg} / \mathrm{kg})$ that provided exposure levels of $1.2 \mu \mathrm{M}$ in the plasma and $0.005 \mu \mathrm{M}$ in the CSF resulting in a $>240$-fold difference (unpublished data by Merck \& Co.). All other reagents were purchased from Sigma-Aldrich Japan or Wako, unless otherwise indicated.

\section{Animals}

Male C57BLKS/J Iar-+Lepr ${ }^{\mathrm{db}} /+\operatorname{Lepr}^{\mathrm{db}}(d b / d b)$ mice and male C57BLKS/J Iar-m+/+Lepr ${ }^{\mathrm{db}}$ mice $(d b / m+)$ were purchased from the Institute for Animal Reproduction (Ibaraki, Japan). Male ddY mice (4 weeks old) purchased from Japan SLC (Shizuoka, Japan) were injected with STZ (150 mg/kg, an intravenous bolus) and used 4 weeks after the injection. STZ-injected mice with blood glucose level above $250 \mathrm{mg} / \mathrm{dL}$ were defined as diabetic and included in this study. The ddY strain was chosen in the STZ experiment, according to previous comparative study (Hayashi et al. 2006). Male mice were used to avoid the influence of the sexually dimorphic expression and regulation of the orexin system on the drug effects (Jöhren 2018). Mice were maintained under a specific pathogenfree condition at $20-26^{\circ} \mathrm{C}$ and allowed free access to a normal chow diet (PicoLab Rodent Diet 20) and water. Turning room lights on at zeitgeber time (ZT) 0 and off at ZT12 were automatically controlled. Since the mice are nocturnal animals, the 12 -h light and 12-h dark phase were referred to as resting and awake phase, respectively, in this study. All experimental procedures were approved by the Committee of Animal Experiments at the University of Toyama (No. A2015PHA-8, A2018PHA-19, A2018PHA-20, A2018MED-40).

\section{Sleep recordings}

The states of sleep and wakefulness in mice were analyzed, as described previously (Tsuneki et al. 2016a). In brief, $d b / m+, d b / d b$ and STZ-diabetic mice were implanted with electrodes (Pinnacle Technology, KS, USA) for electroencephalogram (EEG) and electromyogram (EMG) recordings and housed individually in the recording chamber. After 3 days of recovery, 1-SORA-1, 2-SORA-MK1064, DORA-12 $(30 \mathrm{mg} / \mathrm{kg})$ or vehicle was administered to $d b / m+$ and $d b / d b$, and then EEG and EMG signals were recorded with a data collection system (Pinnacle Technology, USA) for $24 \mathrm{~h}$. Data were analyzed using Sleepsign software (Kissei Comtec, Nagano, Japan).

\section{Glucose and insulin tolerance tests}

For glucose tolerance test, mice were fasted for $16 \mathrm{~h}$, and glucose $(1 \mathrm{~g} / \mathrm{kg})$ was intraperitoneally injected. For insulin tolerance test, mice were deprived from food for $2-4 \mathrm{~h}$, and insulin (2 units/kg) was intraperitoneally injected. Blood samples $(<1 \mu \mathrm{L})$ were collected from the tail vein, and blood glucose levels were measured using a blood glucose meter (FreeStyle Lite, Abbott Japan, Chiba, Japan).

\section{Analysis of serum insulin levels}

For glucose-stimulated insulin secretion test, mice were fasted for $16 \mathrm{~h}$, and glucose $(1 \mathrm{~g} / \mathrm{kg})$ was intraperitoneally injected. Blood samples were obtained from the tail vain of mice using heparinized capillary tubes (Fisher Scientific). Then, serum was prepared by centrifugation $(220 \mathrm{~g}$, $15 \mathrm{~min}, 4^{\circ} \mathrm{C}$ ) and kept frozen at $-80^{\circ} \mathrm{C}$ until used. Insulin levels were measured using ELISA kit (Takara Bio; the inter- and intra-assay variability, $<10 \%$ ) with a microplate reader (FilterMax F5, Molecular Devices), according to the manufacturer's instructions.

\section{Measurements of energy expenditure}

Daily changes in food intake, locomotor activity, $\mathrm{O}_{2}$ consumption, $\mathrm{CO}_{2}$ production, energy expenditure and the respiratory quotient were simultaneously measured for $36 \mathrm{~h}$ using a small animal metabolism-measuring system (MK-5000RQ; Muromachi Kikai, Tokyo, Japan). Outliers in data due to accidental contact between the apparatus and the mice used or their products were detected by the ROUT method and excluded.

\section{Reverse transcription-quantitative PCR}

Tissues were isolated, and the extraction of RNA, reverse transcription and quantitative real-time PCR were carried out, as described previously (Yonezawa et al. 2012). Relative expression level was determined by calculating a ratio of the target mRNA to internal control (ribosomal protein S18 mRNA) in each sample. Primer pairs are shown in Table 1.

\section{Histochemical analysis}

Isolated epididymal white adipose tissue (eWAT) was fixed with $4 \%$ paraformaldehyde and subjected to hematoxylin and eosin staining. To analyze the size of adipocytes, four microscopic images (4× magnification, BX61 upright 
Table 1 PCR primers.

\begin{tabular}{l}
\hline Primer name \\
\hline Pepck \\
Pgc1 $\alpha$ \\
Mcp1 \\
Tnf $\alpha$ \\
Emr1 \\
IL-6 \\
Caspase 1 \\
Selenoprotein P \\
Lect2 \\
Fst315 \\
S18 ribosomal protein
\end{tabular}

\begin{tabular}{l}
\hline Forward \\
\hline CAGGATCGAAAGCAAGACAGT \\
GCCCGGTACAGTGAGTGTTC \\
CCACTCACCTGCTGCTACTCAT \\
AAGCCTGTAGCCCACGTCGTA \\
CTTTGGCTATGGGCTTCCAGTC \\
TTCCATCCAGTTGCCTTCTTGG \\
GGCAGGAATTCTGGAGCTTCAA \\
CCTTGGTTTGCCTTACTCCTTCC \\
ACGTGTGACAGCTATGGCTGTGGACAG \\
TGCTCTTCTGGCGTGCTTCT \\
AGTTCCAGCACATTTTGCGAG
\end{tabular}

\begin{tabular}{l}
\hline Reverse \\
\hline AAGTCCTCTTCCGACATCCAG \\
CTGGGCCGTTTAGTCTTCCT \\
TGGTGATCCTCTTGTAGCTCTCC \\
GGCACCACTAGTTGGTTGTCTTTG \\
GCAAGGAGGACAGAGTTTATCGTG \\
TTCTCATTTCCACGATTTCCCAG \\
GTCAGTCCTGGAAATGTGCC \\
TTTGTTGTGGTGTTTGTGGTGG \\
AGGTATGCTGTGGGGTCACTGGAGTC \\
AAATTGCAGAAAGTTCTGA \\
TCATCCTCCGTGAGTTCTCCA
\end{tabular}

Emr1, EGF-like module-containing mucin-like hormone receptor-like 1; Fst315, follistatin; IL-6, interleukin-6; Lect2, leukocyte cell-derived chemotaxin 2; Mcp1, monocyte chemotactic protein-1; Pepck, phosphoenolpyruvate carboxykinase; Pgc1 $\alpha$, peroxisome proliferator-activated receptor gamma coactivator $1 \alpha$; Tnf $\alpha$, tumor necrosis factor $\alpha$.

microscope, Olympus) were randomly selected from each mouse specimen. The areas of adipocytes ( $>900$ cells in total) were measured and averaged using ImageJ software.

\section{Experimental design}

To examine the drug effects, four independent experiments were conducted. 1-SORA-1 (30 mg/kg), 2-SORA-MK1064 $(30 \mathrm{mg} / \mathrm{kg})$, DORA-12 $(30 \mathrm{mg} / \mathrm{kg})$, DORA-P $(30 \mathrm{mg} / \mathrm{kg})$, diazepam $(10 \mathrm{mg} / \mathrm{kg})$ or vehicle $(0.5 \%$ methyl cellulose 400) were administered orally by gavage. The oral dose of these drugs was chosen, according to the manufacture's instruction (Merck \& Co.) and previous pharmacokinetic and pharmacodynamic studies (Cox et al. 2010, Ramirez et al. 2013, Gotter et al. 2016, Stump et al. 2016). To assess the drug efficacies on glucose metabolism, glucose tolerance after 3 weeks of treatment was used as the primary endpoint, according to our previous study (Tsuneki et al. 2016a). Mice were allocated to one of the four experiments at random and then to one of the treatment groups within each experiment at random with sample size of 4-8 mice per group, as follows:

In experiment 1 , sleep recordings were performed using $d b / m+$ (11 weeks old), $d b / d b$ (11 weeks old), and STZ-diabetic mice (9 weeks old). A drug or vehicle was administered to $d b / m+$ and $d b / d b$ mice at ZTO and subjected to sleep recording for $24 \mathrm{~h}$.

In experiment 2, influences of resting-phase administration of drugs on glucose/energy metabolism were examined in $d b / d b$ mice. Mice (11 weeks old) were treated with the following drugs daily at ZT0 for 7 weeks (all 7 days per week). Mice treated with vehicle, 1-SORA-1, 2-SORA-MK1064 or DORA-12 were cohoused in each cage (i.e., there were four mice per cage). For comparison, mice treated with vehicle, DORA-P (a peripherally acting DORA) or diazepam (a benzodiazepine sedative-hypnotic agent) were cohoused. Glucose tolerance tests were performed at ZT6 after 3 and 4 weeks of the treatment under 16-h fasting conditions. At weeks 4-5, insulin tolerance test was conducted at ZT6 under conditions of 2-h food deprivation. At week 6, glucose-stimulated insulin secretion test was conducted at ZT6 under 16-h fasting conditions, and then in vivo energy expenditure was analyzed using metabolic chambers. At week 7, mice were killed at ZT6 under 6-h fasting condition, and tissues were isolated. The tissue samples were snap frozen by liquid nitrogen and stored at $-80^{\circ} \mathrm{C}$ until used for biochemical analyses. In Fig. 2E, another group of $d b / d b$ mice were similarly prepared for conducting glucosestimulated insulin secretion test conducted at ZT6 under 16-h fasting conditions at week 3.

In experiment 3 , the influences of awake-phase administration of vehicle, 1-SORA-1, 2-SORA-MK1064 and DORA-12 were examined in $d b / d b$ mice. Mice (11 weeks old) were treated at ZT12 every day for 7 weeks. Mice from different treatment groups were cohoused (i.e., four mice per cage). Glucose tolerance tests were performed after 3 and 4 weeks of the treatment at ZT6 or ZT18 under 16-h fasting conditions, respectively. At weeks $4-5$, insulin tolerance test was conducted at ZT6 or ZT18 under conditions of 2-h food deprivation. Measurements of glucose-stimulated insulin secretion and energy expenditure and isolation of tissues were performed using the same procedures as experiment 2 .

In experiment 4 , the effects of 1-SORA-1, 2-SORA-MK1064 or DORA-12 on glucose/energy metabolism were examined in STZ-induced diabetic mice. The drugs were administered at ZTO every day 
for 7 weeks. Mice from different treatment groups were cohoused. Glucose tolerance tests were carried out after 3 weeks of the treatment at ZT6 under 16-h fasting conditions, respectively. At week 4, insulin tolerance test was conducted at ZT6 under conditions of 4-h food deprivation. At week 6, energy expenditure was measured using metabolic chambers. At week 7, mice were killed at ZT6 under 6-h fasting condition, and tissue samples were stored at $-80^{\circ} \mathrm{C}$ until used.

In experiments $2-4$, the same animals underwent a series of these tests.

\section{Statistical analysis}

Data are expressed as mean \pm S.E.M. StatView software (SAS Institute Inc.) was used for statistical analysis. Measurements over time were evaluated by two-way repeated-measures ANOVA where applicable, and the results were summarized in Supplementary Table 1 (see section on supplementary data given at the end of this article). To compare the influences of drug treatment at each time point in the repeated measures design or on non-repeated data (e.g., area under the curve), Student's $t$-test and ANOVA with Bonferroni post hoc test were used to assess the statistically significant differences between two treatment groups and among more than three treatment groups, respectively. In these analyses, oneway ANOVA was used in experiment 1 conducted as a completely randomized design, whereas two-way ANOVA was used in experiment 2-4 conducted as a randomized block design. The $P$ value of less than 0.05 was considered statistically significant.

\section{Results}

\section{Effects of 1-SORA, 2-SORA and DORA on sleep-wake state in diabetic mice}

We compared sleep-wake architecture between type 2 diabetic $d b / d b$ and non-diabetic $d b / m+$ mice after vehicle treatment at the beginning of light phase (ZT0) (Fig. 1 and Supplementary Fig. 1). Vehicle-treated $d b / d b$ mice exhibited increase in total awake time $(7526 \pm 595 \mathrm{~s}$, $n=6, P<0.01)$ and decrease in total NREM sleep time $(6460 \pm 555 \mathrm{~s}, n=6, P<0.05)$ compared to vehicle-treated $d b / m+$ mice (Awake: $4301 \pm 657 \mathrm{~s}, n=3$, NREM: $9348 \pm 651$ s, $n=3$ ) in the early resting phase (ZT2-6) (Supplementary Fig. 1). In the dark-active phase, these sleep-wake parameters were comparable between $d b / d b$ and $d b / m+$ mice.
When DORA-12 was administered at ZT0, these parameters were not significantly altered in $d b / m+$ mice in both light and dark phases (Supplementary Fig. 1). However, in $d b / d b$ mice, administration of 2-SORA-MK1064 or DORA-12 at ZTO rapidly reduced the awake time, and the effects of 2-SORA-MK1064 and DORA-12 lasted 4 and 6h, respectively (Fig. 1A). As a result, total awake time was reduced only in the light phase. 1-SORA-1 did not affect the awake time. Concomitantly, the NREM sleep time was acutely increased by 2-SORA-MK1064 and DORA12 but not 1-SORA-1 (Fig. 1B). Total time in NREM sleep in the light phase was increased by 2-SORA-MK1064 and DORA-12, whereas no statistically significant changes in the dark phase were observed. None of these drugs significantly affected the REM sleep time in both the light and dark phases in $d b / d b$ mice (Fig. 1C). Thus, 2-SORA-MK1064 and DORA-12 promoted the deep sleep without 'next-daysomnolence' in $d b / d b$ mice. Both total awake $(4298 \pm 629 \mathrm{~s}$, $n=7)$ and NREM sleep time $(9644 \pm 648 \mathrm{~s}, n=7)$ during ZT2- 6 in DORA-12-treated $d b / d b$ mice were comparable with respective time in vehicle-treated $d b / m+$ mice (as shown above) (Supplementary Fig. 1). These results indicate that the abnormally reduced sleep in $d b / d b$ mice was restored to control level by single administration of 2-SORA-MK1064 or DORA-12 at resting phase.

On the other hand, STZ-diabetic mice exhibited normal period of wakefulness and NREM sleep in the light phase, when compared to non-diabetic control mice (Supplementary Fig. 2). The REM sleep time was not significantly different between two groups, although a decreasing trend was observed in the STZ-diabetic mice. Also in the dark phase, these sleep-wake parameters were not significantly different between STZ-diabetic and nondiabetic control mice, although there was a trend toward decrease in the awake time and increase in the NREM sleep time in STZ-diabetic mice.

\section{Effects of 1-SORA, 2-SORA and DORA on glucose metabolism in $d b / d b$ mice}

To investigate the effects of 1-SORA-1, 2-SORA-MK1064 and DORA-12 on impaired glucose metabolism in diabetic state, these drugs were administered to $d b / d b$ mice daily at resting phase (ZT0) for 7 weeks. Diabetic $d b / d b$ mice showed severe obesity, and 1-SORA-1, 2-SORA-MK1064 and DORA-12 did not significantly alter the body weight during this period (Fig. 2A). In glucose tolerance tests conducted at week 3 (Fig. 2B), two-way repeated measures ANOVA of blood glucose levels in all treatment groups revealed significant time $\times$ treatment interaction 
A

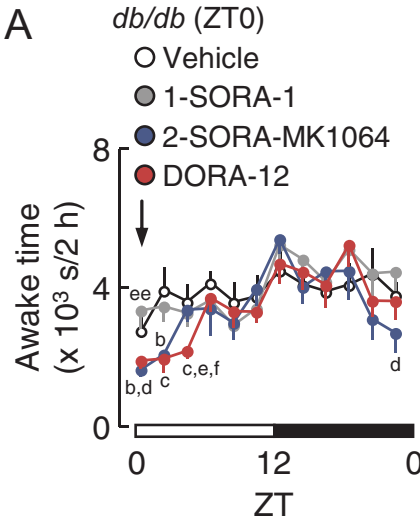

B

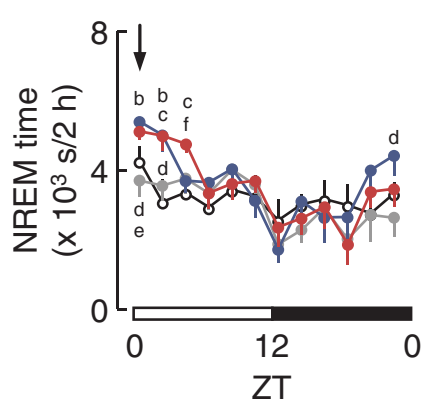

C

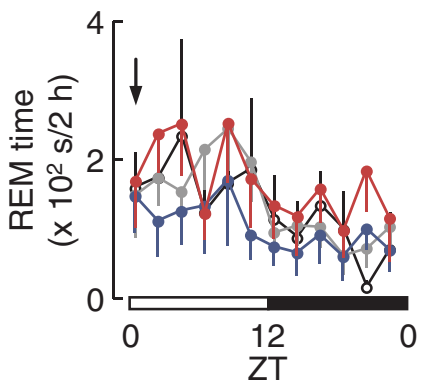

Light phase

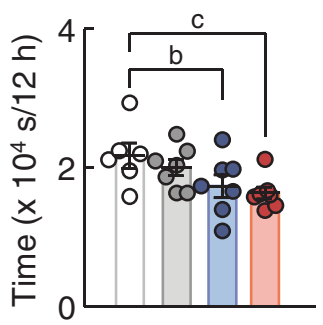

Light phase
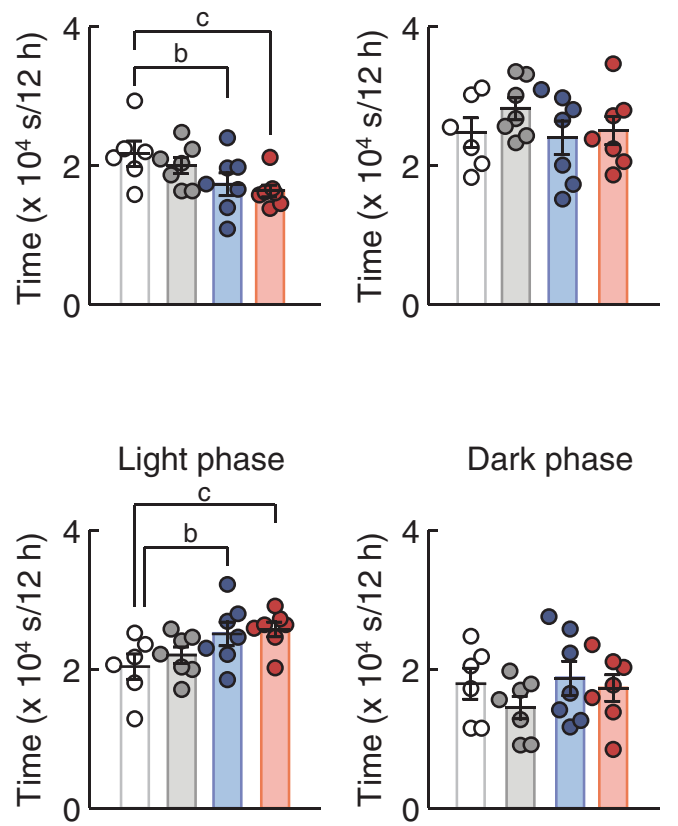

Figure 1

Effects of selective and dual orexin receptor antagonists on sleep and wakefulness in $d b / d b$ mice. Mice were administered vehicle, 1-SORA-1 (a 1-SORA, $30 \mathrm{mg} / \mathrm{kg}$ ), 2-SORA-MK1064 (a 2-SORA $30 \mathrm{mg} / \mathrm{kg}$ ), or DORA-12 (a DORA, $30 \mathrm{mg} / \mathrm{kg}$ ) at ZTO and subjected to sleep recordings for $24 \mathrm{~h}$ to analyze the awake (A), NREM (B) and REM sleep time (C). Left, total time spent in the awake (A), NREM (B) and REM sleep (C) every $2 \mathrm{~h}$. Middle, total time spent in the awake (A), NREM (B), and REM sleep (C) during the 12-h light phase. Right, total time spent in the awake (A), NREM (B) and REM sleep (C) during the 12-h dark phase. Data are presented as the mean \pm S.E.M. $(n=6-7$ per group). ${ }^{\mathrm{P}} P<0.05$ : 2-SORA-MK1064 vs vehicle, $c P<0.05$ : DORA-12 vs vehicle, $d P<0.05$ : 1 -SORA- 1 vs 2 -SORA-MK1064, e $P<0.05$, eе $P<0.01$ : 1-SORA-1 vs DORA-12, $P$ P $<0.05$ : 2-SORA-MK1064 vs DORA-12.

(Supplementary Table 1), and one-way ANOVA with post-hoc test demonstrated that 1-SORA-1 (at 60min), 2-SORA-MK1064 (at 30 and 60 min), and DORA-12 (at 60 and $120 \mathrm{~min}$ ) significantly reduced blood glucose levels compared to those in vehicle-treated group (Fig. 2B). In glucose tolerance tests conducted at week-4 (Fig. 2C), two-way repeated measures ANOVA in all groups revealed significant effects of drug treatment (Supplementary Table 1 ), and one-way ANOVA with post-hoc test demonstrated that 1-SORA-1 (at 120 min), 2-SORA-MK1064 (at 0, 30, 60 , and $120 \mathrm{~min}$ ), and DORA-12 (at 60 and $120 \mathrm{~min}$ ) significantly reduced blood glucose levels compared to those in vehicle-treated group. Glucose area under the curves also showed the glucose lowering effects of all these drugs (Fig. 2C, lower panel). Serum insulin levels before and 15-30 min after (Fig. 2D) or 60-120 min after glucose loading (Fig. 2E) were not significantly affected by these drugs. In insulin tolerance test conducted after 5 weeks of the treatment, no obvious effect was observed (Fig. 2F).

In contrast, resting-phase (ZT0) daily administration of DORA-P, a BBB-impermeable DORA, did not significantly affect body weight gain (Supplementary Fig. 3A) and blood glucose levels during glucose tolerance test conducted at week 3 (Supplementary Fig. 3B) and insulin tolerance test conducted at week 4 (Supplementary Fig. $3 C)$ in $d b / d b$ mice. Moreover, when $d b / d b$ mice were treated with diazepam, a benzodiazepine hypnotic drug, daily at resting phase (ZT0), these metabolic parameters were not significantly affected (Supplementary Fig. 3).

We further examined the effects of 1-SORA-1, 2-SORA-MK1064 and DORA-12 on energy metabolism 

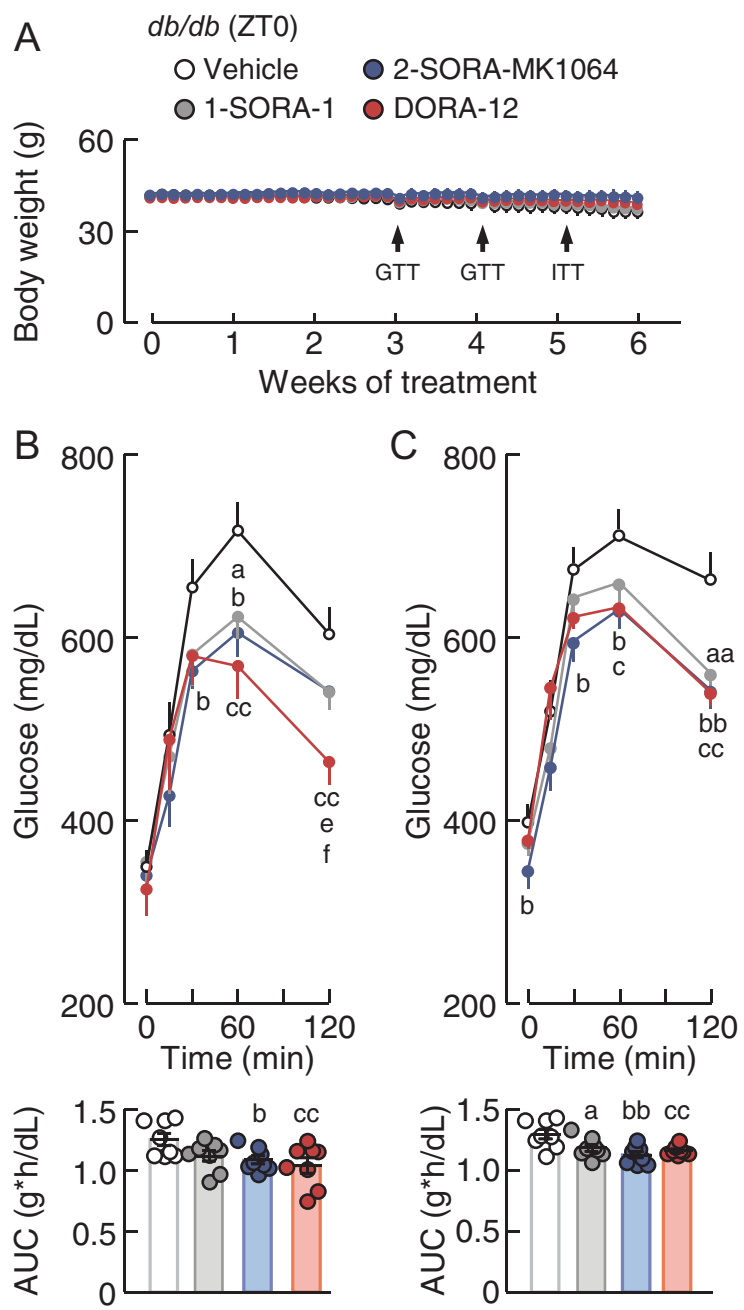
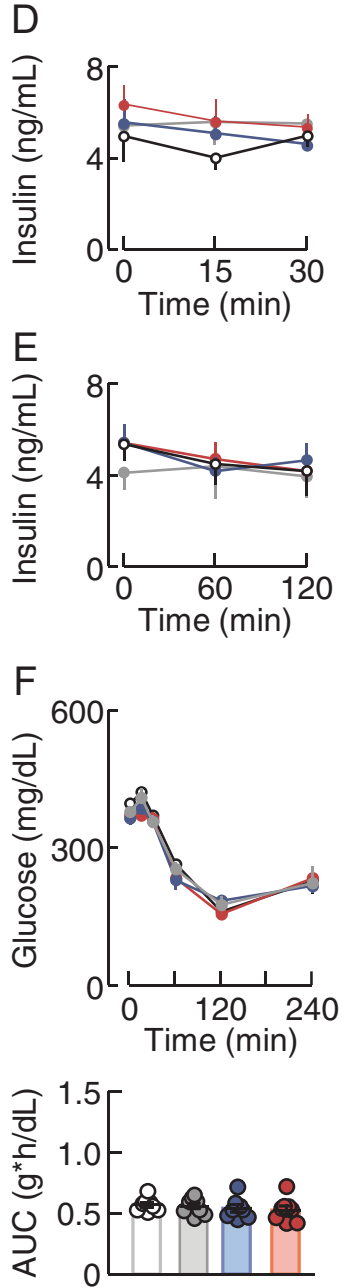

\section{Figure 2}

Influences of resting-phase administration of selective and dual orexin receptor antagonists on glucose metabolism in $d b / d b$ mice. Vehicle, 1-SORA-1 (a 1-SORA, 30 mg/kg), 2-SORA-MK1064 (a 2-SORA, $30 \mathrm{mg} / \mathrm{kg}$ ), or DORA-12 (a DORA, $30 \mathrm{mg} / \mathrm{kg}$ ) was administered daily at ZTO. (A) Body weight changes. (B and C) Glucose tolerance test (GTT) conducted after 3 (B) and 4 weeks (C) of the treatment. Upper panel, time-course of changes in blood glucose levels. Lower panel, area under the curve (AUC) of the changes in blood glucose. ( $D$ and $E$ ) Serum insulin levels in glucosestimulated insulin secretion (GSIS) test conducted at week 6 (D) and week 3 (E). (F) Insulin tolerance test (ITT) conducted after 5 weeks of the treatment. Data are presented as the mean \pm S.E.M. (A, B, C, D and F: $n=8$ per group, E: $n=5$ per group). Data in (E) were obtained in different groups from others. ${ }^{a} P<0.05$ and aa $P<0.01$ : 1-SORA-1 vs vehicle, $\mathrm{b} P<0.05$ and $\mathrm{bb} P<0.01$ : 2-SORA-MK1064 vs vehicle, $c p<0.05$ and $c p<0.01$ : DORA-12 vs vehicle, e $P<0.05: 1$-SORA-1 vs DORA-12, ${ }^{f} P<0.05:$ 2-SORA-MK1064 vs DORA-12. in $d b / d b$ mice. When the drugs were administered daily at ZT0 for 6 weeks, food intake, energy expenditure, locomotor activity and respiratory quotient were not significantly changed (Fig. 3A, B, C and D). Thus, restingphase administration of these drugs did not affect wholebody energy balance.

In contrast to the improved glucose tolerance induced by the orexin receptor antagonists when administered at ZTO (Fig. 2), when 1-SORA-1, 2-SORA-MK1064 or DORA-12 was administered to $d b / d b$ mice daily at the beginning of awake phase (ZT12) for 3-5 weeks, no statistically significant effects of these drugs were observed on body weight (Fig. 4A and Supplementary Fig. 4A) and blood glucose levels during glucose tolerance tests conducted at ZT18 of week-3 when compared to vehicle controls (Fig. 4B). Insulin tolerance test conducted at ZT18 of week 4 also showed no effect (Fig. 4C). Similarly, in glucose tolerance tests conducted at ZT6 of weeks 3 and 4 (Supplementary Fig. 4B and C) and insulin tolerance tests conducted at ZT6 of week 5 (Supplementary Fig. 4D), there were no significant differences in glucose areas under the curves between orexin antagonist- and vehicletreated groups, although the levels were lower in the DORA-12- than the 1-SORA-1- and 2-SORA-MK1064group. Serum insulin levels before and 15-30 min after glucose loading were not significantly affected by these drugs (Supplementary Fig. 4E). No statistically significant changes in food intake, energy expenditure, locomotor activity and respiratory quotient were observed after 6 weeks of the drug treatments (Supplementary Fig. 5A, B, $\mathrm{C}$ and $\mathrm{D})$. Thus, the improvement of glucose tolerance by the orexin antagonists depended on the treatment time of the day.

\section{Effects of 1-SORA, 2-SORA and DORA on gene expression in the liver of $d b / d b$ mice}

To reveal the mechanisms by which resting-phase administration of 1-SORA-1, 2-SORA-MK1064 and DORA-12 improved glucose intolerance in $d b / d b$ mice, 

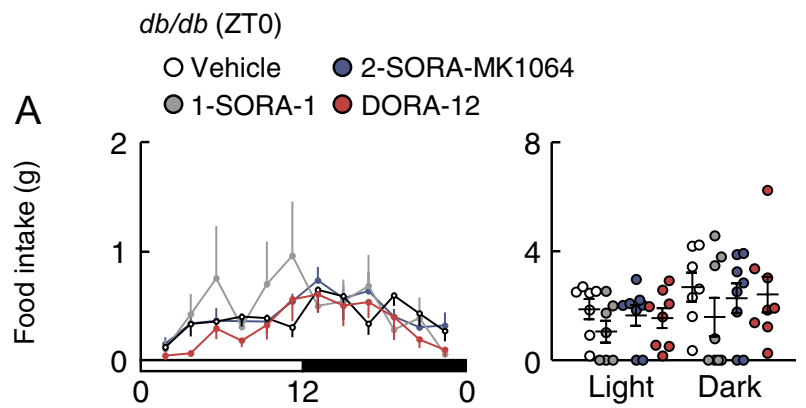

B
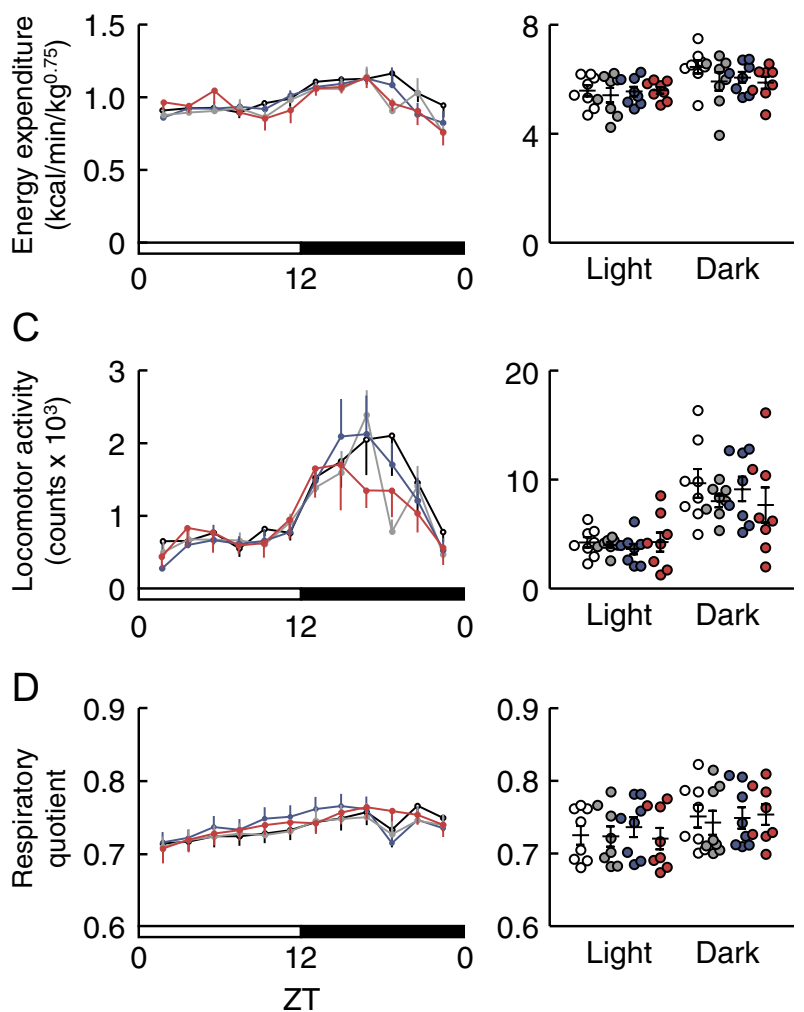

Figure 3

Influences of resting-phase administration of selective and dual orexin receptor antagonists on energy balance in $d b / d b$ mice. Vehicle, 1-SORA-1 (a 1-SORA, 30 mg/kg), 2-SORA-MK1064 (a 2-SORA, 30 mg/kg) or DORA-12 (a DORA, $30 \mathrm{mg} / \mathrm{kg}$ ) was administered daily at ZTO, and the metabolic-cage analysis was conducted after 6 weeks of the treatment. (A, B and C) The drug effects on food intake (A), energy expenditure (B) and locomotor activity $(C)$ were shown. Left, daily changes in the respective levels obtained every $2 \mathrm{~h}$. Right, total levels obtained during the 12-h light and 12-h dark phase. (D) Respiratory quotient. The levels were averaged every $2 \mathrm{~h}$ (Left) or $12 \mathrm{~h}$ during the light and dark phase (Right). Data are presented as the mean \pm S.E.M. ( $n=8$ per group). No significant differences from vehicle group were detected by one-way ANOVA with Bonferroni's test.

gene expression profiles were investigated in the liver where glucose metabolism is coordinately regulated by both hormones and by the central-autonomic nervous system (Schwartz et al. 2013). Concerning chronic inflammatory markers (Fig. 5A), both 2-SORA-MK1064
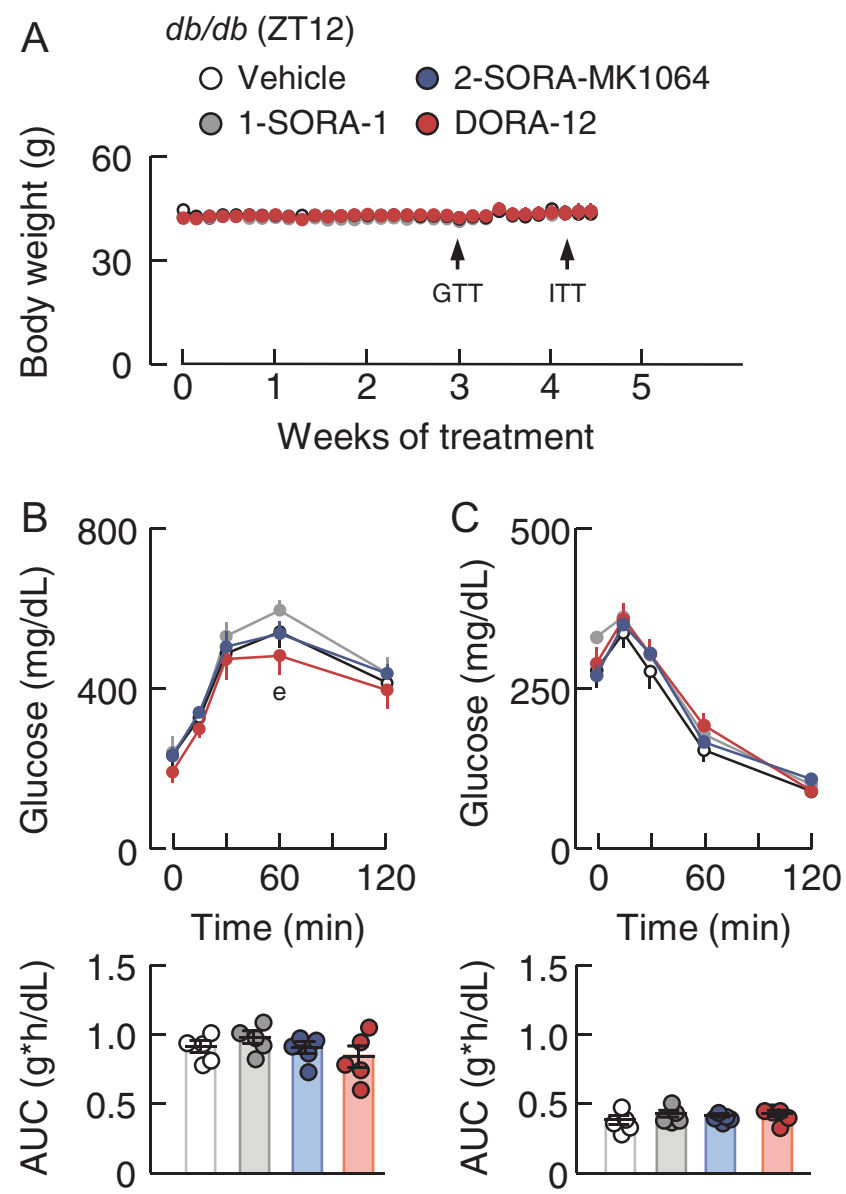

\section{Figure 4}

Influences of awake-phase administration of selective and dual orexin receptor antagonists on glucose metabolism in $d b / d b$ mice. Vehicle, 1-SORA-1 (a 1-SORA, 30 mg/kg), 2-SORA-MK1064 (a 2-SORA, 30 mg/kg), or DORA-12 (a DORA, $30 \mathrm{mg} / \mathrm{kg}$ ) was administered daily at ZT12. (A) Body weight changes. (B) Glucose tolerance test conducted at ZT18 after 3 weeks of the treatment. (C) Insulin tolerance test (ITT) conducted at ZT18 after 4 weeks of the treatment. Upper in B and C, time-course of changes in blood glucose levels. Lower in B and C, area under the curve (AUC) of the changes in blood glucose. Data are presented as the mean \pm S.E.M. ( $n=5$ per group). e $P<0.05: 1$-SORA-1 vs DORA-12.

and DORA-12 significantly decreased the mRNA levels of tumor necrosis factor $\alpha$ (Tnf $\alpha)$ and caspase 1 (Casp1), whereas 1-SORA-1 caused no such effects. The levels of EGF-like module-containing mucin-like hormone receptor-like 1 (Emr1) mRNA encoding F4/80, a macrophage marker, were decreased by DORA-12, and a decreasing trend in the Emr1 levels was observed after the 2-SORA-MK1064 treatment. Also, there was a trend toward decrease in the monocyte chemotactic protein-1 (Mcp1) mRNA levels by 2-SORA-MK1064 and DORA-12. These results indicate that daily resting-phase administration of 2-SORA-MK1064 and DORA-12, but not 1-SORA-1, attenuated chronic inflammation in the 
$d b / d b(Z T O)$

O Vehicle O 2-SORA-MK1064

O 1-SORA-1 O DORA-12

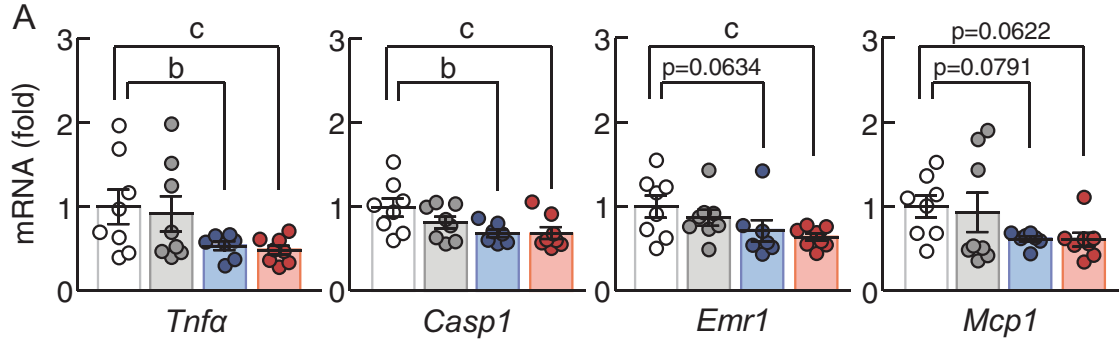

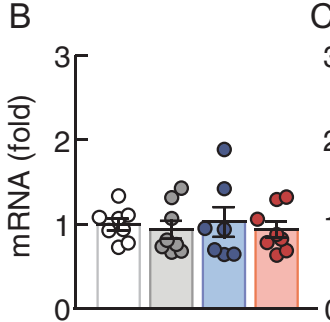

Pepck

C

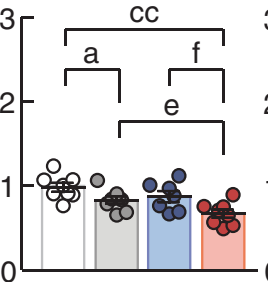

$\mathrm{SeP}$

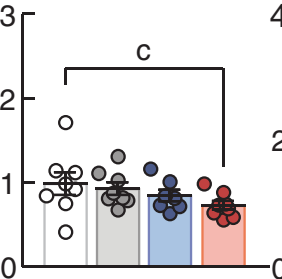

Lect2

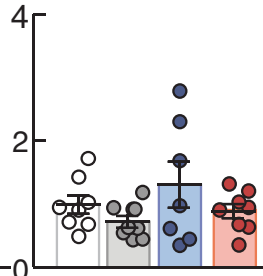

Fst315
Figure 5

Influences of resting-phase administration of selective and dual orexin receptor antagonists on gene expression in the liver of $d b / d b$ mice. Vehicle, 1-SORA-1 (a 1-SORA, $30 \mathrm{mg} / \mathrm{kg}$ ), 2-SORA-MK1064 (a 2-SORA, $30 \mathrm{mg} / \mathrm{kg}$ ), or DORA-12 (a DORA, $30 \mathrm{mg} / \mathrm{kg}$ ) was administered daily at ZTO, and the liver was isolated after 7 weeks of the treatment. (A) The mRNA levels of proinflammatory markers, tumor necrosis factor $\alpha$ (Tnf $\alpha$ ), caspase 1 (Casp1), Emr1 (encoding F4/80) and monocyte chemotactic protein-1 (Mcp1). (B) The mRNA levels of a gluconeogenic factor, phosphoenolpyruvate carboxykinase (Pepck). (C) The mRNA levels of hepatokines, selenoprotein $P$ $(\mathrm{SeP})$, Lect2 and follistatin (Fst315). Data are presented as the mean \pm S.E.M. ( $n=7-8$ per group). a $P<0.05$ : 1-SORA-1 vs vehicle, $\mathrm{b} P<0.05$ : 2-SORA-MK1064 vs vehicle, $c P<0.05, c c P<0.01$ : DORA-12 vs vehicle, e $P<0.05$ : 1 -SORA-1 vs DORA-12, $f P<0.05:$ 2-SORA-MK1064 vs DORA-12. liver of $d b / d b$ mice. The levels of phosphoenolpyruvate carboxykinase (Pepck), a gluconeogenic factor, were not affected by these drugs (Fig. 5B). Selenoprotein P (SeP), leukocyte cell-derived chemotaxin 2 (Lect2) and follistatin (Fst315) are hepatokines that link obesity to impairment of glucose metabolism (Misu et al. 2010, Lan et al. 2014, Tao et al. 2018). The SeP mRNA levels were reduced by 1-SORA-1 and DORA-12 in the liver of $d b / d b$ mice (Fig. 5C). The Lect2 mRNA levels were reduced by DORA-12 (Fig. 5C). The Fst315 mRNA levels were not significantly affected by any of these drugs (Fig. 5C).

\section{Effects of 1-SORA, 2-SORA and DORA on chronic inflammation in the eWAT of $d b / d b$ mice}

Acute sleep loss promotes increased adiposity and adipose tissue inflammation in humans (Cedernaes et al. 2018). We therefore investigated the influences of resting-phase administration of 1-SORA-1, 2-SORA-MK1064 and DORA12 on adipose tissue morphology and inflammatory profiles. When the drugs were daily administered to $d b / d b$ mice at ZTO, hematoxylin and eosin staining demonstrated that the numbers of smaller sized adipocytes in eWAT were increased by treatment with 2-SORA-MK1064 and DORA12, but not 1-SORA-1 (Fig. 6A). The effects of DORA-12 were more evident than those of 2-SORA-MK1064. Gene expression analysis (Fig. 6B) demonstrated that 1-SORA-1, 2-SORA-MK1064 and DORA-12 reduced the Tnf $\alpha$ mRNA levels. 1-SORA-1 and DORA-12 decreased the interleukin-6 (IL-6) levels compared to 2-SORA-MK1064, although the levels were not different from vehicle controls. Moreover, the Emr1 levels were reduced only by 1-SORA-1. The Mcp1 levels were reduced by DORA-12, and 1-SORA-1 showed a decrease trend ( $P=0.177$ vs vehicle). Therefore, restingphase inhibition of orexin-1 and -2 receptors appeared to be relatively preferentially associated with the attenuated inflammatory responses and the adipocyte size reduction, respectively, in the eWAT of $d b / d b$ mice.

\section{Effects of 1-SORA, 2-SORA and DORA on metabolic and inflammatory profiles in STZ-diabetic mice}

We further investigated the effects of 1-SORA-1, 2-SORA-MK1064 and DORA-12 on impaired glucose metabolism in STZ-induced diabetic mice. When the drugs were administered daily at ZTO for 6 weeks, the body weight was not changed (Supplementary Fig. 6A). In glucose tolerance tests conducted at week 3 (Supplementary Fig. 6B), no statistically significant alterations were observed. Systemic insulin sensitivity was largely comparable among four groups in insulin tolerance test (Supplementary Fig. 6C). Thus, these drugs were less effective in STZ-diabetic than type 2 diabetic $d b / d b$ mice (Fig. 2B) in terms of their efficacies on glucose tolerance at week 3. None of these drugs affected food intake, energy expenditure, locomotor activity, respiratory quotient and basal serum insulin levels (Supplementary Fig. 6D, E, F, G and $\mathrm{H}$ ). Moreover, gene expression analysis in STZ-diabetic mice demonstrated that 1-SORA-1, 2-SORA-MK1064 and DORA-12 did not significantly affect the mRNA levels 
A
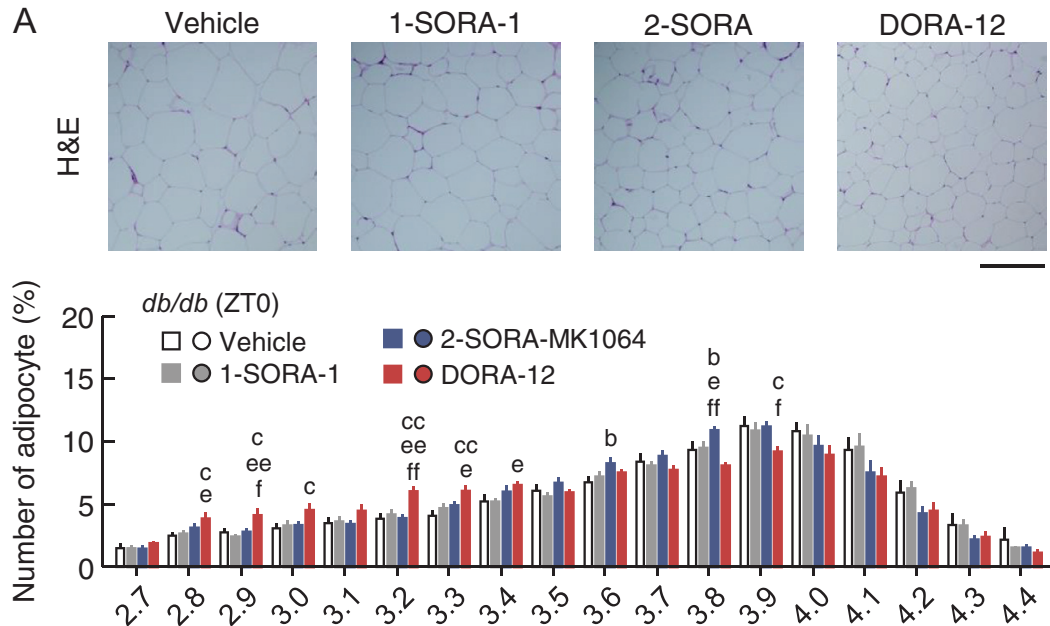

$d b / d b(Z T 0)$

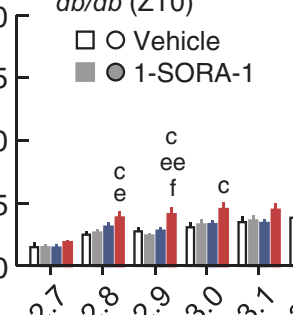

- 2-SORA-MK1064

- O DORA-12

cc

ee $c c$

ff

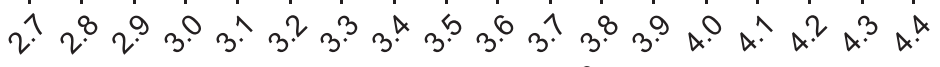

Log cell area $\left(\mu \mathrm{m}^{2}\right)$
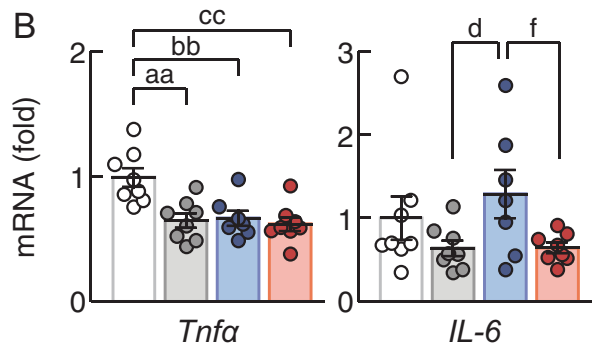

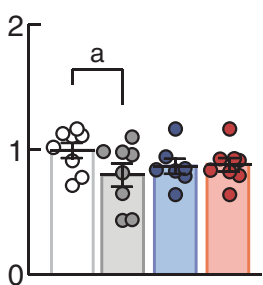

Emr1

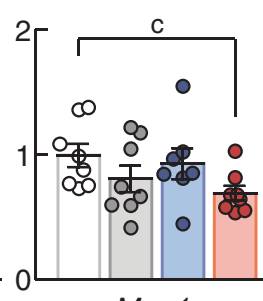

Mcp1

\section{Figure 6}

Influences of resting-phase administration of selective and dual orexin receptor antagonists on the morphology and gene expression in the epididymal white adipose tissue of $d b / d b$ mice. Vehicle, 1-SORA-1 (a 1-SORA, 30 mg/kg), 2-SORA-MK1064 (a 2-SORA, $30 \mathrm{mg} / \mathrm{kg}$ ) or DORA-12 (a DORA, $30 \mathrm{mg} / \mathrm{kg}$ ) was administered daily at ZTO, and the adipose tissue was isolated after 7 weeks of the treatment. (A) Morphological changes. Upper, typical microscopic images showing hematoxylin and eosin (H\&E) staining of the adipose tissue. Scale bar $=200 \mu \mathrm{m}$. Lower, distribution histogram of the adipocyte size. (B) Changes in chronic adipose tissue inflammation. The mRNA levels of proinflammatory markers, Tnf $\alpha$, interleukin-6 (IL-6), Emr1 (encoding F4/80) and $M c p 1$ were analyzed. Data are presented as the mean \pm S.E.M. $(n=7-8$ per group). a $P<0.05$ and aa $P<0.01$ : 1-SORA-1 vs vehicle, b $P<0.05$ and bb $P<0.01$ : 2-SORA-MK1064 vs vehicle, $c P<0.05$ and $c c P<0.01$ : DORA-12 vs vehicle, $d P<0.05$ : 1-SORA-1 vs 2-SORA-MK1064, е $P<0.05$, ее $P<0.01$ : 1 -SORA-1 VS DORA-12, $f$ P $<0.05$, ff $P<0.01$ : 2-SORA-MK1064 vs DORA-12. of hepatic gluconeogenic factors, Pepck and peroxisome proliferator-activated receptor $\gamma$ coactivator $1 \alpha\left(P_{g c} 1 \alpha\right)$ (Supplementary Fig. 7A), hepatic inflammation markers, Emr1 and Tnfo (Supplementary Fig. 7A) and markers of adipose tissue inflammation, Emr1, Tnf $\alpha, M c p 1$ and $I L-6$ (Supplementary Fig. 7B).

\section{Discussion}

To investigate the possible existence of a sleep-dependent mechanism for improving glucose metabolism, we examined the effects of orexin antagonists on sleepwake behavior and glucose metabolism in diabetic mice. In $d b / d b$ mice, the disrupted sleep was improved by 2-SORA-MK1064 and DORA-12, whereas 1-SORA-1 had no influence. Daily resting phase, but not awake administration of these drugs improved glucose intolerance. In these processes, 2-SORA-MK1064 and 1-SORA-1 mainly attenuated chronic inflammation in the liver and eWAT, respectively, and DORA-12 exhibited the combined benefits. No drugs improved glucose intolerance in STZ-diabetic mice that had no apparent abnormality in the sleep-wake behavior. These results suggest that both 1-SORA-type (sleep-independent) and 2-SORA-type (possibly sleep-dependent) mechanisms underlie the chronotherapeutic effects against type 2 diabetes associated with sleep disturbances.

Sleep disorders are more prevalent in patients with type 2 diabetes than control subjects (Tan et al. 2018). Type 2 diabetic animals, including $d b / d b$ mice, also exhibit disrupted sleep-wake architecture (Laposky et al. 2008, Tsuneki et al. 2018). Suvorexant, a DORA, improved the abnormal sleep in $d b / d b$ mice (Tsuneki et al. 2016a); however, the influences of 1-SORAs and 2-SORAs under diabetic conditions had remained unknown. The present study demonstrated that abnormally reduced NREM sleep time and increased awake time in $d b / d b$ mice were rapidly restored after resting-phase administration of DORA12. 2-SORA-MK1064 caused similar effects, whereas 1-SORA-1 showed no effects. Thus, DORA and 2-SORA were both effective to improve sleep disturbances under type 2 diabetic conditions. It should be noted that awakephase administration of suvorexant and C1m (a 2-SORA) induced sleep during the awake phase in a non-timely manner, and their efficacies were greater than those of resting-phase administration in normal mice (Etori et al. 2014). Appropriately timed administrations of these drugs are required for promoting physiological sleep-wake cycle.

Synchronization of sleep-wake behavior with circadian clock rhythm is required for maintaining glucose homeostasis (Gamble et al. 2014). Impaired sleep quality 
is associated with poor glycemic control in humans (Yoda et al. 2015). To assess the presence of functional link between sleep and glucose metabolism from the chronopharmacological point of view, the influences of resting phase and awake phase administrations of orexin antagonists with sleep-promoting effects (i.e., 2-SORA-MK1064 and DORA-12) were compared on glucose metabolism in diabetic mice. The results showed that both drugs improved glucose intolerance in $d b / d b$ mice when administered daily at resting phase, whereas their awake-phase administration failed to improve it. These profiles were consistent with those of suvorexant in our previous study (Tsuneki et al. 2016a). Moreover, the resting-phase administration of 2-SORA-MK1064 and DORA-12 had no effect on glucose intolerance in STZdiabetic mice that exhibited normal sleep during resting phase. These results imply that 2-SORAs and DORAs could improve glucose metabolism in a sleep normalizationdependent manner under conditions of type 2 diabetes mellitus associated with sleep disturbances.

Influences of $\mathrm{GABA}_{\mathrm{A}}$ receptor modulators on glucose metabolism have remained uncertain, because mixed results have been reported (Tsuneki et al. 2016b). In our study, resting-phase administration of diazepam to $d b / d b$ mice had no effect in glucose tolerance test. $\mathrm{GABA}_{\mathrm{A}}$ receptor modulators are known to induce sleep which is different form normal physiological one promoted by DORAs (Fox et al. 2013, Ramirez et al. 2013, Gotter et al. 2014). Moreover, zolpidem, a $\mathrm{GABA}_{\mathrm{A}}$ receptor modulator, has been reported to affect the activity of neurons in the dorsal motor nucleus of the vagus (Gao \& Smith 2010) which regulate autonomic projections from the hypothalamus for maintaining glucose homeostasis (Pocai et al. 2005). Potential benefit of $\mathrm{GABA}_{\mathrm{A}}$ receptor-mediated sleep on glucose metabolism might be compromised by these alterations. Continuous promotion of physiological sleep that can be achieved by 2-SORAs and DORAs may be valuable for ameliorating glucose metabolism, possibly via improvement of autonomic nerve balance.

Systemic and cellular inflammation is known to be inhibited by cognitive behavioral therapy against insomnia in elderly subjects (Irwin et al. 2014, 2016). Sufficient sleep elevates the parasympathetic tones (Castro-Diehl et al. 2016), and the parasympathetic nerve activation inhibits inflammation in the liver (Bonaz et al. 2016). Chronic inflammation in the liver causes dysregulation of glucose homeostasis (Mayoral Monibas et al. 2016). In our study, 2-SORA-MK1064 and DORA-12 reduced the expression of proinflammatory factors (i.e., Tnf $\alpha$, Casp1, Emr1 and Mcp1 mRNA) in the liver of $d b / d b$ mice.
Therefore, the improvement of glucose intolerance by 2-SORA and DORA may be at least partly due to sleepinduced attenuation of chronic inflammation in the liver.

1-SORA-1 is an agent without the sleep-inducing effect; unexpectedly however, it also improved metabolic functions in a treatment-time-of-day-dependent manner. Resting-phase administration of 1-SORA-1 improved glucose intolerance and reduced the mRNA expression of Tnfa and Emr1 in the eWAT, whereas its awake-phase administration caused no effects. Consistently, chronic awake-phase administration of ACT-335827 (a 1-SORA) had little impacts on glucose and lipid metabolism in dietinduced obese rats (Steiner et al. 2013). The mechanisms underlying the anti-inflammatory effects of 1-SORA-1 remain unknown; however, we anticipate the involvement of sympathetic nervous system innervating the white adipose tissues (1) because orexin-1, but not orexin-2 receptors are expressed in hypothalamic paraventricular nucleus, a major sympathetic regulatory region (Fan et al. 2018), (2) because blockade of orexin-1 receptors attenuates excessive vasomotor tone via sympathetic overactivity (Xiao et al. 2013), (3) because obesity causes sympathetic overactivity, leading to adipose tissue dysfunctions and chronic inflammation (Guarino et al. 2017, Saxton et al. 2019) and (4) because $d b / d b$ mice exhibit sustained increase in sympathetic tones throughout the day (Goncalves et al. 2009). Therefore, 1-SORA-1 and DORA12 may induce anti-inflammatory effects in the eWAT of $d b / d b$ mice by inhibiting the orexin- 1 receptor-mediated sympathetic overactivity, resulting in the improvement of glucose metabolism.

Our pharmacological approach to detect the sleepdependent improvement of glucose metabolism has several limitations. First, we cannot completely rule out the possibility that sleep and glucose metabolism were concomitantly, but independently, improved after treatment with orexin antagonists. Interestingly, awakephase administration of almorexant, a DORA, reduced sympathetic overactivity in hypertensive $\mathrm{BPH} / 2 \mathrm{~J}$ mice, whereas its resting-phase administration showed no effect (Jackson et al. 2016). DORAs might improve glucose metabolism in a sleep-dependent and -independent manner at different time of the day. Secondly, altered diurnal variations in the drug-targeted molecules under type 1 and type 2 diabetic conditions, if any, might affect the chronopharmacological profiles of orexin antagonists in this study. However, daily oscillations of preproorexin mRNA were flattened in diet-induced obese mice compared to normal mice (Kohsaka et al. 2007), although those in $d b / d b$ and STZ-diabetic mice remain unknown. 
Orexin-2 receptors are constantly expressed throughout the day in rat hypothalamus, despite daily increase in orexin-1 receptors at awake phase (Wang et al. 2017). Therefore, the influences of these factors on sleepdependent regulations seemed to be limited. Thirdly, the present results did not sufficiently reveal the relationship between the improvement in glucose metabolism and inflammation profile in $d b / d b$ mice due to the drug treatments. Further study is required to clarify these pathophysiological and chronotherapeutic mechanisms.

Notably, previous studies using orexin-deficient mice showed that daily oscillation of orexin action is required for maintaining glucose/energy homeostasis (Tsuneki et al. 2008 , 2018). Moreover, central administration of orexin A at awake, but not resting phase improved hyperglycemia via reduction of hepatic glucose production in $d b / d b$ mice (Tsuneki et al. 2015). Taken together with the present findings, appropriately timed administrations of orexin agonists appear to be compatible and/or synergistic with those of orexin antagonists for improving glucose metabolism, since both treatments are useful to enhance daily rhythmic actions of endogenous orexin.

Recently, acute subcutaneous injection and chronic intraperitoneal infusion of orexin A at pharmacological dose have been shown to improve glycemic control in type 2 diabetic animal models (Park et al. 2015, Kaczmarek et al. 2017). Peripheral orexin receptors are involved in these effects, because orexin A enhanced insulin secretion and protected pancreatic islets from apoptotic cell death in vitro. However, functional significance of endogenous orexin A in the periphery remains uncertain because of its lower levels in plasma than cerebrospinal fluid (Strawn et al. 2010). In our study, DORA-12-induced improvement of glucose metabolism in $d b / d b$ mice was considered to be mediated by central orexin receptors, because DORA-P, a BBB-impermeable DORA had no effect. Furthermore, 1-SORA-1, 2-SORA-MK1064 and DORA-12 did not affect the glucose-stimulated insulin secretion. Thus, central, rather than peripheral orexin receptors appear to be a target more relevant to the chronotherapy against type 2 diabetes.

In conclusion, we found that 2-SORA-MK1064 improved sleep, glucose metabolism and inflammation profiles in $d b / d b$ mice, suggesting the presence of a sleepdependent mechanism behind these effects. 1-SORA-1 exerted sleep-independent improvements, and DORA-12 showed the combined benefits of both drugs. A largescale study to clarify the benefits of pharmacological sleep extension with 2-SORAs and DORAs in type 2 diabetic patients with sleep disturbances is considered to be warranted.

\section{Supplementary data}

This is linked to the online version of the paper at https://doi.org/10.1530/ JOE-18-0708.

\section{Declaration of interest}

The authors declare that there is no conflict of interest that could be perceived as prejudicing the impartiality of the research reported.

\section{Funding}

Funding for this study was provided by MSD K K, Tokyo, Japan (to T S). This project was also supported by JSPS and ISF under the Japan-Israel Research Cooperative Program, JSPS KAKENHI (Grant Numbers JP15K09380, JP15K15599, JP18K08468 and JP19H05011), the Naito Foundation (to T S), the Smoking Research Foundation (to H T), the Foundation for Growth Science (to $T$ S), the Japan Diabetes Foundation (to $T S$ ), Budget for Functional Enhancement from University of Toyama (to T S and H T) and Toyama Pharmaceutical Valley Development Consortium (to T S and H T).

\section{Acknowledgments}

The authors thank T Matsushima and T Fujimori (University of Toyama, Toyama, Japan) for their technical assistance.

\section{References}

Andrews SP, Aves SJ, Christopher JA \& Nonoo R 2016 Orexin receptor antagonists: historical perspectives and future opportunities. Current Topics in Medicinal Chemistry 16 3438-3469. (https://doi.org/10.2174/ 1568026616666150929111607)

Bonaz B, Sinniger V \& Pellissier S 2016 Anti-inflammatory properties of the vagus nerve: potential therapeutic implications of vagus nerve stimulation. Journal of Physiology 594 5781-5790. (https://doi. org/10.1113/JP271539)

Castro-Diehl C, Diez Roux AV, Redline S, Seeman T, McKinley P, Sloan R \& Shea S 2016 Sleep duration and quality in relation to autonomic nervous system measures: the multi-ethnic study of atherosclerosis (MESA). Sleep 39 1927-1940. (https://doi.org/10.5665/sleep.6218)

Cedernaes J, Schiöth HB \& Benedict C 2015 Determinants of shortened, disrupted, and mistimed sleep and associated metabolic health consequences in healthy humans. Diabetes 64 1073-1080. (https:// doi.org/10.2337/db14-1475)

Cedernaes J, Schönke M, Westholm JO, Mi J, Chibalin A, Voisin S, Osler M, Vogel H, Hörnaeus K, Dickson SL, et al. 2018 Acute sleep loss results in tissue-specific alterations in genome-wide DNA methylation state and metabolic fuel utilization in humans. Science Advances 4 eaar8590. (https://doi.org/10.1126/sciadv.aar8590)

Cox CD, Breslin MJ, Whitman DB, Schreier JD, McGaughey GB, Bogusky MJ, Roecker AJ, Mercer SP, Bednar RA, Lemaire W, et al. 2010 Discovery of the dual orexin receptor antagonist [(7R)-4-(5-chloro1,3-benzoxazol-2-yl)-7-methyl-1,4-diazepan-1-yl][5-methyl-2-(2H1,2,3-triazol-2-yl)phenyl]methanone (MK-4305) for the treatment of https://joe.bioscientifica.com

https://doi.org/10.1530/JOE-18-0708 (c) 2019 Society for Endocrinology Published by Bioscientifica Ltd. Printed in Great Britain 
insomnia. Journal of Medicinal Chemistry 53 5320-5332. (https://doi. org/10.1021/jm100541c)

Donga E, van Dijk M, van Dijk JG, Biermasz NR, Lammers GJ, van Kralingen KW, Corssmit EP \& Romijn JA 2010 A single night of partial sleep deprivation induces insulin resistance in multiple metabolic pathways in healthy subjects. Journal of Clinical Endocrinology and Metabolism 95 2963-2968. (https://doi.org/10.1210/jc.2009-2430)

Etori K, Saito YC, Tsujino N \& Sakurai T 2014 Effects of a newly developed potent orexin- 2 receptor-selective antagonist, compound $1 \mathrm{~m}$, on sleep/wakefulness states in mice. Frontiers in Neuroscience 88 . (https://doi.org/10.3389/fnins.2014.00008)

Fan Y, Jiang E, Hahka T, Chen QH, Yan J \& Shan Z 2018 Orexin A increases sympathetic nerve activity through promoting expression of proinflammatory cytokines in Sprague Dawley rats. Acta Physiologica 222 e13011. (https://doi.org/10.1111/apha.12963)

Fox SV, Gotter AL, Tye SJ, Garson SL, Savitz AT, Uslaner JM, Brunner JI, Tannenbaum PL, McDonald TP, Hodgson R, et al. 2013 Quantitative electroencephalography within sleep/wake states differentiates $\mathrm{GABA}_{\mathrm{A}}$ modulators eszopiclone and zolpidem from dual orexin receptor antagonists in rats. Neuropsychopharmacology 38 2401-2408. (https:// doi.org/10.1038/npp.2013.139)

Gamble KL, Berry R, Frank SJ \& Young ME 2014 Circadian clock control of endocrine factors. Nature Reviews: Endocrinology 10 466-475. (https://doi.org/10.1038/nrendo.2014.78)

Gao H \& Smith BN 2010 Zolpidem modulation of phasic and tonic GABA currents in the rat dorsal motor nucleus of the vagus. Neuropharmacology 58 1220-1227. (https://doi.org/10.1016/j. neuropharm.2010.03.003)

Goncalves AC, Tank J, Diedrich A, Hilzendeger A, Plehm R, Bader M, Luft FC, Jordan J \& Gross V 2009 Diabetic hypertensive leptin receptor-deficient $\mathrm{db} / \mathrm{db}$ mice develop cardioregulatory autonomic dysfunction. Hypertension 53 387-392. (https://doi.org/10.1161/ HYPERTENSIONAHA.108.124776)

Gotter AL, Roecker AJ, Hargreaves R, Coleman PJ, Winrow CJ \& Renger JJ 2012 Orexin receptors as therapeutic drug targets. Progress in Brain Research 198 163-188. (https://doi.org/10.1016/B978-0-444-594891.00010-0)

Gotter AL, Garson SL, Stevens J, Munden RL, Fox SV, Tannenbaum PL, Yao L, Kuduk SD, McDonald T, Uslaner JM, et al. 2014 Differential sleep-promoting effects of dual orexin receptor antagonists and $\mathrm{GABA}_{\mathrm{A}}$ receptor modulators. BMC Neuroscience 15 109. (https://doi. org/10.1186/1471-2202-15-109)

Gotter AL, Forman MS, Harrell CM, Stevens J, Svetnik V, Yee KL, Li X, Roecker AJ, Fox SV, Tannenbaum PL, et al. 2016 Orexin 2 receptor antagonism is sufficient to promote NREM and REM sleep from mouse to man. Scientific Reports 6 27147. (https://doi.org/10.1038/ srep27147)

Guarino D, Nannipieri M, Iervasi G, Taddei S \& Bruno RM 2017 The role of the autonomic nervous system in the pathophysiology of obesity. Frontiers in Physiology 8 665. (https://doi.org/10.3389/ fphys.2017.00665)

Hayashi K, Kojima R \& Ito M 2006 Strain differences in the diabetogenic activity of streptozotocin in mice. Biological and Pharmaceutical Bulletin 29 1110-1119. (https://doi.org/10.1248/bpb.29.1110)

Haynes AC, Chapman H, Taylor C, Moore GB, Cawthorne MA, Tadayyon M, Clapham JC \& Arch JR 2002 Anorectic, thermogenic and anti-obesity activity of a selective orexin-1 receptor antagonist in ob/ob mice. Regulatory Peptides 104 153-159. (https://doi. org/10.1016/S0167-0115(01)00358-5)

Irwin MR, Olmstead R, Carrillo C, Sadeghi N, Breen EC, Witarama T, Yokomizo M, Lavretsky H, Carroll JE, Motivala SJ, et al. 2014 Cognitive behavioral therapy vs. Tai Chi for late life insomnia and inflammatory risk: a randomized controlled comparative efficacy trial. Sleep 37 1543-1552. (https://doi.org/10.5665/sleep.4008)

Irwin MR, Olmstead R \& Carroll JE 2016 Sleep disturbance, sleep duration, and inflammation: a systematic review and meta-analysis of cohort studies and experimental sleep deprivation. Biological Psychiatry 80 40-52. (https://doi.org/10.1016/j.biopsych.2015.05.014)

Jackson KL, Dampney BW, Moretti JL, Stevenson ER, Davern PJ, Carrive P \& Head GA 2016 Contribution of orexin to the neurogenic hypertension in BPH/2J mice. Hypertension 67 959-969. (https://doi. org/10.1161/HYPERTENSIONAHA.115.07053)

Jöhren O 2018 Orexins/hypocretins and sex. Peptides 99 115-116. (https://doi.org/10.1016/j.peptides.2017.10.014)

Kaczmarek P, Skrzypski M, Pruszynska-Oszmalek E, Sassek M, Kolodziejski PA, Billert M, Szczepankiewicz D, Wojciechowicz T, Maechler P, Nowak KW, et al. 2017 Chronic orexin-A (hypocretin-1) treatment of type 2 diabetic rats improves glucose control and betacell functions. Journal of Physiology and Pharmacology 68 669-681.

Knutson KL \& Van Cauter E 2008 Associations between sleep loss and increased risk of obesity and diabetes. Annals of the New York Academy of Sciences 1129 287-304. (https://doi.org/10.1196/annals.1417.033)

Kohsaka A, Laposky AD, Ramsey KM, Estrada C, Joshu C, Kobayashi Y, Turek FW \& Bass J 2007 High-fat diet disrupts behavioral and molecular circadian rhythms in mice. Cell Metabolism 6 414-421. (https://doi.org/10.1016/j.cmet.2007.09.006)

Lan F, Misu H, Chikamoto K, Takayama H, Kikuchi A, Mohri K, Takata N, Hayashi H, Matsuzawa-Nagata N, Takeshita Y, et al. 2014 LECT2 functions as a hepatokine that links obesity to skeletal muscle insulin resistance. Diabetes 63 1649-1664. (https://doi.org/10.2337/db130728)

Laposky AD, Bradley MA, Williams DL, Bass J \& Turek FW 2008 Sleepwake regulation is altered in leptin-resistant $(d b / d b)$ genetically obese and diabetic mice. American Journal of Physiology: Regulatory, Integrative and Comparative Physiology 295 R2059-R2066. (https://doi. org/10.1152/ajpregu.00026.2008)

Mahler SV, Moorman DE, Smith RJ, James MH \& Aston-Jones G 2014 Motivational activation: a unifying hypothesis of orexin/hypocretin function. Nature Neuroscience 17 1298-1303. (https://doi.org/10.1038/ nn.3810)

Mayoral Monibas R, Johnson AM, Osborn O, Traves PG \& Mahata SK 2016 Distinct hepatic macrophage populations in lean and obese mice. Frontiers in Endocrinology 7 152. (https://doi.org/10.3389/ fendo.2016.00152)

Mieda M 2017 The roles of orexins in sleep/wake regulation. Neuroscience Research 118 56-65. (https://doi.org/10.1016/j.neures.2017.03.015)

Misu H, Takamura T, Takayama H, Hayashi H, Matsuzawa-Nagata N, Kurita S, Ishikura K, Ando H, Takeshita Y, Ota T, et al. 2010 A liver-derived secretory protein, selenoprotein $\mathrm{P}$, causes insulin resistance. Cell Metabolism 12 483-495. (https://doi.org/10.1016/j. cmet.2010.09.015)

Morairty SR, Revel FG, Malherbe P, Moreau JL, Valladao D, Wettstein JG, Kilduff TS \& Borroni E 2012 Dual hypocretin receptor antagonism is more effective for sleep promotion than antagonism of either receptor alone. PLoS ONE 7 e39131. (https://doi.org/10.1371/journal. pone.0039131)

Park JH, Shim HM, Na AY, Bae JH, Im SS \& Song DK 2015 Orexin A regulates plasma insulin and leptin levels in a time-dependent manner following a glucose load in mice. Diabetologia 58 1542-1550. (https://doi.org/10.1007/s00125-015-3573-0)

Pocai A, Obici S, Schwartz GJ \& Rossetti L 2005 A brain-liver circuit regulates glucose homeostasis. Cell Metabolism 1 53-61. (https://doi. org/10.1016/j.cmet.2004.11.001)

Qian J \& Scheer FAJL 2016 Circadian system and glucose metabolism: implications for physiology and disease. Trends in Endocrinology and Metabolism 27 282-293. (https://doi.org/10.1016/j.tem.2016.03.005)

Ramirez AD, Gotter AL, Fox SV, Tannenbaum PL, Yao L, Tye SJ, McDonald T, Brunner J, Garson SL, Reiss DR, et al. 2013 Dual orexin receptor antagonists show distinct effects on locomotor performance, ethanol interaction and sleep architecture relative to gammaaminobutyric acid-A receptor modulators. Frontiers in Neuroscience $\mathbf{7}$ 254. (https://doi.org/10.3389/fnins.2013.00254) https://joe.bioscientifica.com

https://doi.org/10.1530/JOE-18-0708 (c) 2019 Society for Endocrinology Published by Bioscientifica Ltd. Printed in Great Britain 
Reutrakul S \& Van Cauter E 2018 Sleep influences on obesity, insulin resistance, and risk of type 2 diabetes. Metabolism: Clinical and Experimental 84 56-66. (https://doi.org/10.1016/j.metabol.2018.02.010)

Saxton SN, Withers SB \& Heagerty AM 2019 Emerging roles of sympathetic nerves and inflammation in perivascular adipose tissue. Cardiovascular Drugs and Therapy 33 245-259. (https://doi. org/10.1007/s10557-019-06862-4)

Schwartz MW, Seeley RJ, Tschöp MH, Woods SC, Morton GJ, Myers MG \& D'Alessio D 2013 Cooperation between brain and islet in glucose homeostasis and diabetes. Nature 503 59-66. (https://doi. org/10.1038/nature12709)

Steiner MA, Sciarretta C, Pasquali A \& Jenck F 2013 The selective orexin receptor 1 antagonist ACT-335827 in a rat model of diet-induced obesity associated with metabolic syndrome. Frontiers in Pharmacology 4 165. (https://doi.org/10.3389/fphar.2013.00165)

Strawn JR, Pyne-Geithman GJ, Ekhator NN, Horn PS, Uhde TW, Shutter LA, Baker DG \& Geracioti Jr TD 2010 Low cerebrospinal fluid and plasma orexin-A (hypocretin-1) concentrations in combat-related posttraumatic stress disorder. Psychoneuroendocrinology 35 1001-1007. (https://doi.org/10.1016/j.psyneuen.2010.01.001)

Stump CA, Cooke AJ, Bruno J, Cabalu TD, Gotter AL, Harell CM, Kuduk SD, McDonald TP, O'Brien J, Renger JJ, et al. 2016 Discovery of highly potent and selective orexin 1 receptor antagonists (1-SORAs) suitable for in vivo interrogation of orexin 1 receptor pharmacology. Bioorganic and Medicinal Chemistry Letters 26 5809-5814. (https://doi. org/10.1016/j.bmcl.2016.10.019)

Tan X, van Egmond L, Chapman CD, Cedernaes J \& Benedict C 2018 Aiding sleep in type 2 diabetes: therapeutic considerations. Lancet: Diabetes and Endocrinology 6 60-68. (https://doi.org/10.1016/S2213-8587(17)30233-4)

Tao R, Wang C, Stöhr O, Qiu W, Hu Y, Miao J, Dong XC, Leng S, Stefater M, Stylopoulos N, et al. 2018 Inactivating hepatic follistatin alleviates hyperglycemia. Nature Medicine 24 1058-1069. (https://doi. org/10.1038/s41591-018-0048-0)

Toi N, Inaba M, Kurajoh M, Morioka T, Hayashi N, Hirota T, Miyaoka D, Emoto M \& Yamada S 2019 Improvement of glycemic control by treatment for insomnia with suvorexant in type 2 diabetes mellitus. Journal of Clinical and Translational Endocrinology 15 37-44. (https:// doi.org/10.1016/j.jcte.2018.12.006)

Tsuneki H, Murata S, Anzawa Y, Soeda Y, Tokai E, Wada T, Kimura I, Yanagisawa M, Sakurai T \& Sasaoka T 2008 Age-related insulin resistance in hypothalamus and peripheral tissues of orexin knockout mice. Diabetologia 51 657-667. (https://doi.org/10.1007/s00125-0080929-8)

Tsuneki H, Tokai E, Nakamura Y, Takahashi K, Fujita M, Asaoka T, Kon K, Anzawa Y, Wada T, Takasaki I, et al. 2015 Hypothalamic orexin prevents hepatic insulin resistance via daily bidirectional regulation of autonomic nervous system in mice. Diabetes 64 459-470. (https:// doi.org/10.2337/db14-0695)

Tsuneki H, Kon K, Ito H, Yamazaki M, Takahara S, Toyooka N, Ishii Y, Sasahara M, Wada T, Yanagisawa M, et al. 2016a Timed inhibition of orexin system by suvorexant improved sleep and glucose metabolism in type 2 diabetic $d b / d b$ mice. Endocrinology 157 4146-4157. (https:// doi.org/10.1210/en.2016-1404)

Tsuneki H, Sasaoka T \& Sakurai T 2016b Sleep control, GPCRs, and glucose metabolism. Trends in Endocrinology and Metabolism 27 633-642. (https://doi.org/10.1016/j.tem.2016.06.011)

Tsuneki H, Wada T \& Sasaoka T 2018 Chronopathophysiological implications of orexin in sleep disturbances and lifestyle-related disorders. Pharmacology and Therapeutics 186 25-44. (https://doi. org/10.1016/j.pharmthera.2017.12.010)

Wang D, Opperhuizen AL, Reznick J, Turner N, Su Y, Cooney GJ \& Kalsbeek A 2017 Effects of feeding time on daily rhythms of neuropeptide and clock gene expression in the rat hypothalamus. Brain Research 1671 93-101. (https://doi.org/10.1016/j. brainres.2017.07.006)

Xiao F, Jiang M, Du D, Xia C, Wang J, Cao Y, Shen L \& Zhu D 2013 Orexin A regulates cardiovascular responses in stress-induced hypertensive rats. Neuropharmacology 67 16-24. (https://doi. org/10.1016/j.neuropharm.2012.10.021)

Yoda K, Inaba M, Hamamoto K, Yoda M, Tsuda A, Mori K, Imanishi Y, Emoto M \& Yamada S 2015 Association between poor glycemic control, impaired sleep quality, and increased arterial thickening in type 2 diabetic patients. PLOS ONE 10 e0122521. (https://doi. org/10.1371/journal.pone.0122521)

Yonezawa R, Wada T, Matsumoto N, Morita M, Sawakawa K, Ishii Y, Sasahara M, Tsuneki H, Saito S \& Sasaoka T 2012 Central versus peripheral impact of estradiol on the impaired glucose metabolism in ovariectomized mice on a high-fat diet. American Journal of Physiology: Endocrinology and Metabolism 303 E445-E456. (https://doi. org/10.1152/ajpendo.00638.2011)

Received in final form 18 July 2019

Accepted 7 August 2019

Accepted Preprint published online 7 August 2019 https://joe.bioscientifica.com

https://doi.org/10.1530/JOE-18-0708 (c) 2019 Society for Endocrinology Published by Bioscientifica Ltd. Printed in Great Britain 